\title{
EARLY AUDITORY EVENT-RELATED POTENTIALS ARE ACCELERATED AT PRESCHOOL AGE AFTER EXTREMELY PRETERM BIRTH
}

\author{
H. Hövel ${ }^{1}$, E. Partanen ${ }^{2}$, M. Lindgren ${ }^{3}$, I. Rosén ${ }^{4}$, K. Stjernqvist ${ }^{3}$, M. Huotilainen ${ }^{2,5}$, V. Fellman ${ }^{1,6}$ \\ ${ }^{1}$ Pediatrics, Clinical Sciences, Lund University, Lund, Sweden, ${ }^{2}$ Cognitive Brain Research Unit, Finnish \\ Centre of Excellence in Interdisciplinary Music Research, University of Helsinki, Helsinki, Finland, \\ ${ }^{3}$ Psychology, Lund University, ${ }^{4}$ Neurophysiology, Lund University Hospital, Lund, Sweden, ${ }^{5}$ Finnish Institute \\ of Occupational Health, ${ }^{6}$ Pediatrics, Clinical Sciences, University of Helsinki, Helsinki, Finland
}

Background and aims: Auditory event-related potentials (aERP) are neurophysiological correlates of higher cortical functions. Pathological aERP have been seen in children with various cognitive dysfunctions. Our aim was to study whether aERP in extremely preterm infants (EP) with high risk of dysfunction are different from late preterm (PC) and term-born controls (TC) at preschool age.

Methods: EP $(\mathrm{n}=70)$ born at $26.0 \pm 1.6($ mean \pm SD) gestational weeks $(\mathrm{gw})$, PC born at $32+0$ to $35+0 \mathrm{gw}$ $(n=12)$, and TC $(n=15)$ were studied at 4-5.3 years of age. EEG was recorded while the children listened to a repeated standard tone, randomly replaced by one of three deviants (different frequency, perceived sound location, or duration). Latencies and mean amplitudes (maximum amplitude $\pm 30 \mathrm{~ms}$ ) for the main obligatory responses were measured, as well as mean amplitudes over consecutive 50 ms-intervals.

Results: EP showed faster N1, P1 and N2 responses than PC (central electrodes $p<0.05$ except N2, $p=0.067$ ) and TC $(\mathrm{p}<0.03)$ on most electrodes, but not for later responses $(\mathrm{N} 2, \mathrm{P} 3)$. The P1 peak was significantly weaker for EP $(2.08 \pm 1.61 \mu \mathrm{V})$ than for PC $(3.15 \pm 1.74 \mu \mathrm{V} ; \mathrm{p}=0.039)$ or TC $(3.34 \pm 2.42 \mu \mathrm{V} ; \mathrm{p}=0.014)$. Mean amplitudes for $50 \mathrm{~ms}$ intervals between $100-200 \mathrm{~ms}$ (TC) or 100-250 ms (PC) were significantly lower in EP. These evoked aERP patterns were similar for the standard and all three deviant sounds.

Conclusions: AERP showed consistent group differences suggesting an atypical and weakened sound processing in EP. Children with hearing deficits (cochlear implants), reading deficits, and attentional problems have shown similar patterns. 